\title{
Effect of Secondary Raw Material on the Change of Single Extensive Elongation of Non-Woven Fabrics
}

\author{
S.U.Patxullaev, D.H.Isaeva, Sh.P.Shumqorova, X.I.Yodgorova, R.I.Orazbayeva
}

\begin{abstract}
The article describes research studies in the laboratories of the departments of "Spinning Technology" and "Silk Technology". For this purpose were taken samples of cotton fiber and silk waste from the carding machine in the spinning process, $100 \%$ cotton fiber waste, $50 \%$ cotton fiber, $30 \%$ silk, $20 \%$ mulberry bark fiber, $70 \%$ cotton fiber, $15 \%$ silk, $15 \%$ mulberry bark fiber, non-woven fabrics were produced from $75 \%$ cotton fiber 10\% silk 15\% mulberry bark fiber blends. The single-period elongation deformation of the obtained non-woven fabrics was determined using the device "Stoyka".
\end{abstract}

Keywords: total deformation composition, elastic, plastic deformations, relaxation process, middle square value, coefficient of variation, significant or insignificant indicators

\section{INTRODUCTION}

A number of essential tasks facing the textile industry today include re-equipment of enterprises, introduction of new technologies, ensuring the efficient use of raw materials, full use of secondary raw materials and fiber waste, increasing the range of new products, increasing exports. At the same time, the issue of increasing the production of non-woven fabrics and the range of products in the country is also very important. In the world practice research work is carried out aimed at the production of new techniques and technologies, identifying important factors that affect the technological processes of production of nonwovens. In this field, the introduction of methods of fiber separation from mulberry tree post in the efficient use of secondary resources, the wider involvement of secondary raw materials and waste, the study of the impact of secondary raw materials on the technological

Revised Manuscript Received on May 8, 2020.

* Correspondence Author

Sarvarjon Patxullayev Ubaydulla og'li*, Faculty of textile Technology, Tashkent Institute of Textile and Light Industry, Tashkent, Uzbekistan

Senior teacher Isaeva Dilfuza Hamidovna, Faculty of Technology of Light Industry and Design, Tashkent Institute of Textile and Light Industry, Tashkent, Uzbekistan

Senior teacher Shumqorova Shamsiya Pulatovna, Faculty Technology of light industry, Jizzakh polytechnic institute, Jizzakh Uzbekistan

Senior teacher Yodgorova Xilola Isroilovna, Faculty Technology of light industry, Jizzakh polytechnic institute, Jizzakh, Uzbekistan Technology of Textile, Tashkent Institute of Textile and Light Industry, Tashkent, Uzbekistan

(C) The Authors. Published by Blue Eyes Intelligence Engineering and Sciences Publication (BEIESP). This is an open access article under the CC BY-NC-ND license (http://creativecommons.org/licenses/by-nc-nd/4.0/)
Doctorant (PhD) Orazbayeva Rayxan Izmuratovna, Faculty

performance of non-wovens, improving the quality of non-wovens, the impact of secondary raw materials on the physical properties of non-wovens is important.

The mechanical properties of nonwoven fabrics indicate their response to the effects of various forces. These forces, on the other hand are different, they can be large or small, and they can act once or repeatedly. The forces can act on the length, width, or angle of the non-woven fabrics to a certain extent. As a result, bending, stretching, twisting, etc. deformations occur in the fabric.

The forces acting on non-woven fabrics are not very large. The complete elongation caused by such force is composed of flexible, elastic and plastic parts.

The complete elongation and its parts that occur when stretched are included in the single-cycle mechanical properties. All parts of the full elongation appear and develop at the same time as the material is subjected to force.

The elastic part is formed with great speed and changes the external connections insignificantly due to the adhesion of the fibers in the fabric. If the fabric contains wool fibers, it will not wrinkle, because the elastic deformation will be more, if there are cotton, silk, wool fibers, it will wrinkle, because if the fabric contains elastic fibers, it will wrinkle, and if the fabric contains bast fibers, wrinkling will be a little more difficult, because plastic deformation will be more.

The elastic part is formed over a period of time, and under its influence the bundle in the structure of the fabric change, resulting in new-looking bundles.

The plastic part is associated with irreversible changes in the external and internal connections in the fabric and brings the components that make up the fabric into a different structure.

After non-woven fabrics are released from the action of force, they undergo a process of return to their original state, called relaxation. The elastic elongation disappears along with the force received. The elastic elongation gradually disappears after the force is applied, and the plastic elongation does not disappear. The ratio of elastic, elastic and plastic elongation of non-woven fabrics depends on the fiber content and affects their shrinkage, as well as the ability of the garment to retain its image.

\section{METHODOLOGY}

The variation of flexible, elastic and plastic elongations of non-woven fabrics depending on the composition of the secondary raw material was studied and the test results obtained are given in table 1 below.

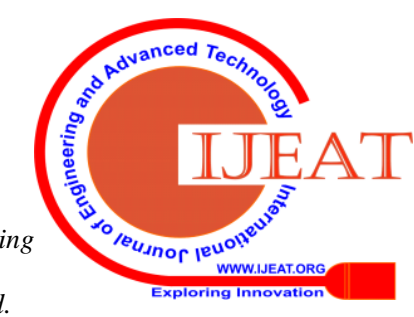




\section{Effect of Secondary Raw Material on the Change of Single Extensive Elongation of Non-Woven Fabrics}

Table 1 Influence of the amount of secondary raw material on the change of single-cycle deformation composition of nonwoven fabrics

\begin{tabular}{|c|c|c|c|c|c|}
\hline \multirow{2}{*}{$o / n$} & \multirow{2}{*}{$\begin{array}{l}\text { Non-woven fabric } \\
\text { containing } \\
\text { secondary investigation } \\
\text { amount, \% }\end{array}$} & \multirow{2}{*}{$\begin{array}{l}\text { Total deformation } \\
\text { content, \% }\end{array}$} & \multicolumn{3}{|c|}{ Percentages of total deformation composition } \\
\hline & & & flexible & elastic & plastic (rest) \\
\hline 1. & $100 \%$ cotton & 8,0 & 0,33 & 0,33 & 0,33 \\
\hline 2. & silk $20 \%$ mulberry bark fiber & 6,0 & 0,57 & 0,33 & 0,10 \\
\hline 3. & $\begin{array}{l}70 \% \text { cotton } 15 \% \text { silk } 15 \% \\
\text { mulberry bark fiber }\end{array}$ & 6,0 & 0,50 & 0,35 & 0,15 \\
\hline 4. & $\begin{array}{l}75 \% \text { cotton } 10 \% \text { silk } 15 \% \\
\text { mulberry bark fiber }\end{array}$ & 6,0 & 0,50 & 0,38 & 0,12 \\
\hline
\end{tabular}

\section{RESULTS AND DISCUSSION}

Analyzing the results of the study, compared with the performance of non-wovens obtained from $100 \%$ cotton fiber secondary raw material, the total deformation content of non-wovens from 50\% cotton. 30\% silk, 20\% mulberry bark fiber decreased by $25.0 \%$, elastic deformation content increased by $42,0 \%$, elastic deformation composition did not change, plastic (residual) deformation content decreased by $70.0 \%, 70 \%$ cotton, $15 \%$ silk, $15 \%$ mulberry bark fiber total deformation content decreased by $25.0 \%$, elastic deformation content increased by $34.0 \%$, elastic deformation content increased by $5.7 \%$, plastic (residual) deformation content increased by decreased by 54,0\%, 75\% cotton $10 \%$ silk $15 \%$ mulberry bark fiber total deformation content decreased by $25.0 \%$, elastic deformation content increased by $34.0 \%$, elastic deformation content increased by $13.0 \%$, plastic (residue ) deformation content decreased by 63.0\%.

The analysis of the results of the study of the determination of mechanical properties showed that the higher the elastic deformation content, the lower the plastic (residual) deformation content, while the non-woven fabrics use more fiber and silk waste from mulberry trees.

For example, in option 2, 50\% cotton, 30\% silk, 20\% mulberry bark fiber increases the elastic deformation content of the non-woven, the main reason for the decrease in the plastic (residual) deformation content is that when we determine the cyclic elongation deformation of the fibers proves that change. Compared to the secondary raw materials of cotton fiber and silk, it was found that the fiber obtained from mulberry bark has a higher elastic deformation and less plastic (residual) deformation.

The research results showed that if we obtain non-woven fabrics from $100 \%$ cotton fiber secondary raw material composition, the elastic deformation content decreases and the plastic (residual) deformation content increases. In addition, the total deformation content of the non-woven fabric of option $250 \%$ cotton $30 \%$, silk $20 \%$, mulberry bark fiber decreased by $25.0 \%$, while the elastic deformation content increased by $42.0 \%$ compared to the performance of non-woven from $100 \%$ cotton fiber secondary raw material. plastic (residual) deformation content was found to decrease by $70.0 \%$.

The results obtained for single-cycle elongation deformation of nonwoven fabrics were compared by criteria.

Indicators of elastic deformation of non-woven fabrics are given in table 2 below.
Table 2

\begin{tabular}{|c|c|c|c|c|}
\hline \multirow[b]{2}{*}{$o / n$} & \multirow{2}{*}{$\begin{array}{l}\text { Containing non-woven fabric } \\
\text { secondary raw material composition }\end{array}$} & \multicolumn{3}{|l|}{ Indicators } \\
\hline & & $\bar{X}$ average & $G$ dispersion & $\begin{array}{l}C \text { variation } \\
\text { coefficients }\end{array}$ \\
\hline 1. & $\begin{array}{l}\text { Non-woven fabric made from } 100 \% \\
\text { cotton fiber waste }\end{array}$ & 0,575 & 0,014 & 2,435 \\
\hline 2. & $\begin{array}{l}50 \% \text { cotton } 30 \% \text { silk } 20 \% \text { non-woven } \\
\text { fabric made from mulberry bark fibers }\end{array}$ & 0,331 & 0,017 & 5,136 \\
\hline 3. & $\begin{array}{l}70 \% \text { cotton } 15 \% \text { silk } 15 \% \text { non-woven } \\
\text { fabric made from mulberry bark fibers }\end{array}$ & 0,509 & 0,030 & 5,89 \\
\hline 4. & $\begin{array}{l}75 \% \text { cotton } 10 \% \text { silk } 15 \% \text { non-woven } \\
\text { fabric made from mulberry bark fibers }\end{array}$ & 0,503 & 0,021 & 4,175 \\
\hline
\end{tabular}

The indicators of non-woven fabric obtained from 100\% cotton fiber waste was compared with the indicator of non-woven fabric obtained from $50 \%$ cotton $30 \%$, silk $20 \%$, mulberry bark fiber.

1. The arithmetic mean is calculated using the following formula:

$$
\begin{gathered}
t_{p a c(\bar{X})}=\frac{\left|\bar{X}_{A}-\bar{X}_{B}\right| \sqrt{n(n-1)}}{\sqrt{S_{A}^{2}+S_{B}^{2}}}=\frac{|0,575-0,331| \sqrt{10 \cdot(10-1)}}{\sqrt{0,00265+0,00289}}=31,10 \\
t_{p a c}=31,10>t_{\text {maб }}=2,1
\end{gathered}
$$

2. The root mean square value is calculated using the following formula:

$t_{p a c(G)}=\frac{\left|G_{A}-G_{B}\right| \sqrt{n(n-1)}}{\sqrt{S_{A}^{2}+S_{B}^{2}}}=\frac{|0,014-0,017| \sqrt{10 \cdot(10-1)}}{\sqrt{0,00265+0,00289}}=0,38$

3. The coefficient of variation is calculated using the following formula:

$t_{p a c(C)}=\frac{\left|C_{A}-C_{B}\right| \sqrt{n(n-1)}}{\sqrt{S_{A}^{2}+S_{B}^{2}}}=\frac{|5,136-2,435| \sqrt{10 \cdot(10-1)}}{\sqrt{0,00265+0,00289}}=344,3$

The indicator of non-woven fabric made from $50 \%$ cotton, $30 \%$ silk, $20 \%$ mulberry bark fibers was compared with the performance of $70 \%$ cotton $15 \%$ silk $15 \%$ mulberry bark fiber.

1. The arithmetic mean is calculated as follows:

$$
\begin{gathered}
t_{p a c(\bar{X})}=\frac{\left|\bar{X}_{A}-\bar{X}_{B}\right| \sqrt{n(n-1)}}{\sqrt{S_{A}^{2}+S_{B}^{2}}}=\frac{|0,509-0,575| \sqrt{10 \cdot(10-1)}}{\sqrt{0,00265+0,01089}}=8,4 \\
t_{p a c}=8,4>t_{\text {таб }}=2,1
\end{gathered}
$$

2. The root mean square value is calculated using the following formula:

$t_{p a c(G)}=\frac{\left|G_{A}-G_{B}\right| \sqrt{n(n-1)}}{\sqrt{S_{A}^{2}+S_{B}^{2}}}=\frac{|0,030-0,014| \sqrt{10 \cdot(10-1)}}{\sqrt{0,00265+0,01089}}=2,0$

3. The coefficient of variation is calculated using the following formula:

$t_{\text {pac }(C)}=\frac{\left|C_{A}-C_{B}\right| \sqrt{n(n-1)}}{\sqrt{S_{A}^{2}+S_{B}^{2}}}=\frac{|5,89-2,435| \sqrt{10 \cdot(10-1)}}{\sqrt{0,00265+0,01089}}=440,68$

The indicatoe of non-woven fabric obtained from 50\% cotton, 30\% silk, 20\% mulberry bark fiber was compared with the performance of non-woven fabric obtained from $75 \%$ cotton, $10 \%$ silk, 15\% mulberry bark fiber.

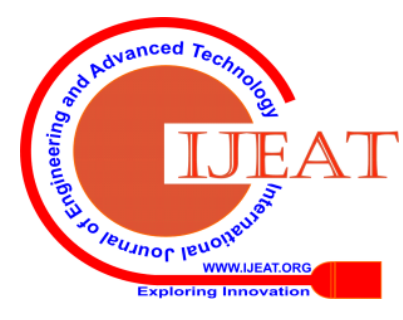


1. The arithmetic mean is calculated as follows:

$$
\begin{gathered}
t_{p a c(\bar{X})}=\frac{\left|\bar{X}_{A}-\bar{X}_{B}\right| \sqrt{n(n-1)}}{\sqrt{S_{A}^{2}+S_{B}^{2}}}=\frac{|0,503-0,575| \sqrt{10 \cdot(10-1)}}{\sqrt{0,00265+0,01089}}=9,1 \\
t_{p a c}=9,1>t_{\text {mаб }}=2,1
\end{gathered}
$$

2. The root mean square value is calculated using the following formula:

$$
t_{p a c(G)}=\frac{\left|G_{A}-G_{B}\right| \sqrt{n(n-1)}}{\sqrt{S_{A}^{2}+S_{B}^{2}}}=\frac{|0,021-0,014| \sqrt{10 \cdot(10-1)}}{\sqrt{0,00265+0,01089}}=0,89
$$

3. The coefficient of variation is calculated using the following formula:

$$
t_{\text {pac }(C)}=\frac{\left|C_{A}-C_{B}\right| \sqrt{n(n-1)}}{\sqrt{S_{A}^{2}+S_{B}^{2}}}=\frac{|4.175-2,435| \sqrt{10 \cdot(10-1)}}{\sqrt{0,00265+0,01089}}=221,8
$$

\begin{tabular}{|c|c|c|c|c|}
\hline \multirow[b]{2}{*}{$o / n$} & \multirow[b]{2}{*}{$\begin{array}{l}\text { Containing non-woven fabric } \\
\text { secondary raw material composition }\end{array}$} & \multicolumn{3}{|l|}{ Indicators } \\
\hline & & $t_{\text {pac }(\bar{X})}$ & $\begin{array}{l}t_{\text {pac }(O)} \text { average } \\
\text { square value }\end{array}$ & \begin{tabular}{|l|}
$\begin{array}{l}\text { pac (C) } \\
\text { variation } \\
\text { coefficients }\end{array}$ \\
\end{tabular} \\
\hline 1. & $\begin{array}{l}\text { Non-woven fabric with indicators of } 100 \% \\
\text { cotton fiber waste } 50 \% \text { cotton } 30 \% \text { silk } 20 \% \\
\text { mulberry bark fiber }\end{array}$ & 31,10 & 0,38 & 344,3 \\
\hline 2. & $\begin{array}{l}50 \% \text { cotton } 30 \% \text { silk } 20 \% \text { molberry bark with } \\
\text { nom-woven fobric performance 70\% cotton } \\
15 \% \text { silk } 15 \% \text { mulberry bark fiber } \\
\text { performance }\end{array}$ & 8,4 & $2,2,0$ & 4440,68 \\
\hline 3. & $\begin{array}{l}50 \% \text { cotton } 30 \% \text { silk } 20 \% \text { mulberry bark } \\
\text { fiber with nono-woven fabric performance } \\
775 \% \text { cotton } 10 \% \text { silk } 15 \% \text { mulberry bark } \\
\text { fiber performance }\end{array}$ & 2.1 & \begin{tabular}{|l|l|} 
\\
\end{tabular} & 221,8 \\
\hline
\end{tabular}

The results of the criterion analyze are presented in table 3.

Table 3

The results of the analysis show that when we compare the performance of non-woven fabric from $100 \%$ cotton fiber waste with $50 \%$ cotton $30 \%$ silk $20 \%$ mulberry bark fiber non-woven fabric, the average deviation is 31.10 , the standard deviation is 0.38 , the coefficient of variation is 344.5 , $50 \%$ cotton, 30\% silk, $20 \%$ mulberry bark fiber non-woven fabric compared with the indicator of non-woven fabric 70\% cotton, $15 \%$ silk, $15 \%$ mulberry bark fiber non-woven fabric TOS average of $8.4 \%$, when we compare the mean square deviation of 2.0, the coefficient of variation of 440.68 , the indicator of non-woven fabric from $50 \%$ cotton $30 \%$, silk $20 \%$, mulberry fiber and the elastic deformation of non-woven fabric from $75 \%$ cotton, $10 \%$ silk, $15 \%$ mulberry fiber the mean was 2.1 , the standard deviation was 0.89 , and the coefficient of variation was 221.8. It can be seen that the elastic deformation of non-woven fabric obtained from 50\% cotton, 30\% silk, $20 \%$ mulberry bark fibers was observed to differ sharply from the tabular values.

\section{CONCLUSION}

Analysis of the obtained results showed that the indicators of non-woven fabric obtained from 50\% cotton, 30\% silk, $20 \%$ mulberry bark fiber on the elastic deformation of non-woven fabrics was better than the performance of non-woven fabrics obtained from other raw materials.

\section{REFERENCES}

1. Patxullayev S. U., Islambekova N. M., Kulmetov M., Ochilov T. A., Valieva Z. F. Determination of the Quality Characteristics of Fibers Obtained From Mulberry Bark. International Journal of Recent Technology and Engineering (IJRTE) ISSN: 2277-3878, Volume-8 Issue-5, January 2020.

2. 2.Waisi, B.I., Arena, J.T., Benes, N.E., Nijmeijer, A., McCutcheon, J.R. Activated carbon nanofiber nonwoven for removal of emulsified oil from water. 2020. Microporous and Mesoporous Materials 296,109966.

3. Gai, X.-L., Cai, Z.-N., Xing, T., (...), Zhang, B., Guan, X.-W. Experimental study on sound absorbing property of spatial absorber of non-woven fabric with micro-perforated plate-like structure. 2020 Applied Acoustics 160,107156.

4. $\quad$ Ren, W., Zhu, H., Yang, Y., (...), Zhao, G., Liu, Y. Flexible and robust silver coated non-woven fabric reinforced waterborne polyurethane films for ultra-efficient electromagnetic shielding. 2020. Composites Part B: Engineering 184,107745.

5. Enes, E., Kipöz, Ş. The role of fabric usage for minimization of cut-and-sew waste within the apparel production line: Case of a summer dress. 2020. Journal of Cleaner Production 248,119221.

6. Wang, J., Ma, C., Chen, G., Dai, P. Interlaminar fracture toughness and conductivity of carbon fiber/epoxy resin composite laminate modified by carbon black-loaded polypropylene non-woven fabric interleaves. 2020. Composite Structures 234,111649.

7. Jedvert, K., Idström, A., Köhnke, T., Alkhagen, M. Cellulosic nonwovens produced via efficient solution blowing technique. 2020. Journal of Applied Polymer Science 137(5),48339.

8. Chen, K., Ghosal, A., Yarin, A.L., Pourdeyhimi, B. Modeling of spunbond formation process of polymer nonwovens. 2020. Polymer 187,121902 .

9. Wang, Z., Yan, F., Pei, H., (...), Fang, K., Li, J. Environmentally-friendly halloysite nanotubes@chitosan/polyvinyl alcohol/non-woven fabric hybrid membranes with a uniform hierarchical porous structure for air filtration. 2020. Journal of Membrane Science 594,117445.

10. Islambekova N.M., Patxullaev S., Azamatov U.N., Khaydarov S.S Study of the Properties of Fibers Obtained From Mulberry Fiber. International Journal of Advanced Research in Science, Engineering and Technology. Vol.6, Issue 5, May 2019.

11. Patkhullaev Sarvarjon, Ochilov Tulkin Ashurovich, Abdugaffarov Abdusattar Abdujabbarovich, Ubaydullayeva Dilora Xamidovna, Valieva Zulfiya Fakhritdinovna, Taniberdiyev Farrux Rustamovich. Change of Qualitative characteristics of Fibers Produced from the Tark Mulberry Tree Branches. International Journal of Advanced Research in Science,Engineering and Technology Vol. 7, Issue 1, January 2020.

12. Patkhullaev Sarvarjon, Ochilov Tulkin Ashurovich, Abdugaffarov Abdusattar Abdujabbarovich, Ubaydullayeva Dilora Xamidovna,Valieva Zulfiya Fakhritdinovna, Taniberdiyev Farrux Rustamovich. Change of the Mechanical Properties of Fibers Produced From Bark of Mulberry Trees. International Journal of Advanced Research in Science, Engineering and Technology Vol. 7, Issue 1 , January 2020

\section{AUTHORS PROFILE}

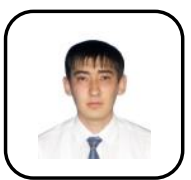

Sarvarjon Patxullayev Ubaydulla og'li,

Faculty of textile Technology, Tashkent Institute of Textile and Light Industry, Tashkent, Uzbekistan

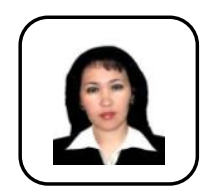

Senior teacher Isaeva Dilfuza Hamidovna

Faculty of Technology of Light Industry and Design, Tashkent Institute of Textile and Light Industry, Tashkent, Uzbekistan

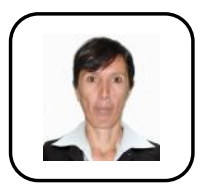

Senior teacher Shumqorova Shamsiya Pulatovna, Faculty Technology of light industry, Jizzakh polytechnic institute, Jizzakh Uzbekistan

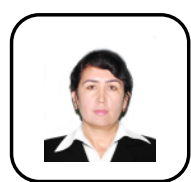

Senior teacher Yodgorova Xilola Isroilovna,

Faculty Technology of light industry, Jizzakh polytechnic institute, Jizzakh, Uzbekistan

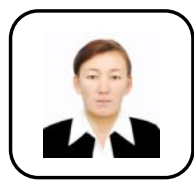

Doctorant (PhD) Orazbayeva Rayxan Izmuratovna, Faculty Technology of Textile, Tashkent Institute of Textile and Light Industry, Tashkent, Uzbekistan

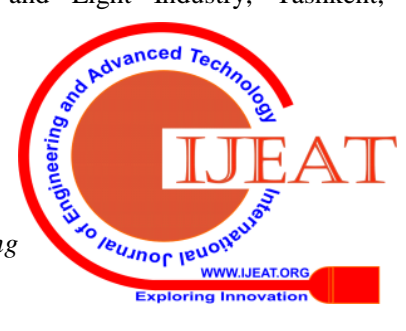

